Submitted: 2 December 2021 | Accepted in revised version: 28 December 2021| Published: 31 December 2021

\title{
Transformation pathways towards sustainable urban development by the inclusion of peri-urban farmland in green infrastructure strategies
}

\begin{abstract}
Urbanization and agricultural land use are two of the main drivers of global changes with effects on ecosystem functions and human wellbeing. Green infrastructure is a new and promising approach in spatial planning contributing to sustainable urban development, but rarely considers spatial and functional potentials of utilizable agricultural land as an integral part. This doctoral thesis addresses this gap and investigates how peri-urban farmland can promote green infrastructure development and sustainable urban development. The results contribute to the conceptual understanding of urban green infrastructures as a strategic spatial planning approach that incorporates inner-urban utilizable agricultural land and the agriculturally dominated landscape at the outer urban fringe. Four strategies are introduced for spatial planning with the contribution to a strategically planned multifunctional network. Finally, this thesis sheds light on the opportunities that arise from the integration of peri-urban farmland in the green infrastructure concept to support transformation towards a more sustainable urban development. This work concludes that the linkage of peri-urban farmland with the green infrastructure concept is a promising action field for the development of new pathways for urban transformation towards sustainable urban development. Along with these outcomes, attention is drawn to limitations that remain to be addressed by future research.
\end{abstract}

\section{Keywords:}

urban agriculture, planning strategies, spatial planning, sustainability transformation, urban, sustainable development

\section{Werner Rolf}

Chair for Strategic Landscape Planning and Management, Technical University of Munich, TUM School of Life Sciences, EmilRamann-Str. 6, D-85354 Freising, Germany

Email: werner.rolf@tum.de

https://orcid.org/0000-0001-7040-034X 


\section{Introduction}

Land use is one of the primary drivers of global changes with effects on ecosystem functions and human wellbeing (MEA, 2005). Two very recent global assessments - the 'Global assessment report on biodiversity and ecosystem services of the Intergovernmental Science-Policy Platform on Biodiversity and Ecosystem Services' (IPBES, 2019) and the special report on 'Climate Change and Land' of the Intergovernmental Panel on Climate Change (IPCC, 2019) present compelling evidence of the effects of land use and the need for sustainable land management, underpinning the urgency of the current state and trends and the need for change. Both studies identified urbanization and unsustainable agricultural intensification as two of the main drivers of global changes with effects on ecosystem functions and human wellbeing. The impact of modern agriculture on ecosystems, biodiversity and human wellbeing has been widely discussed and the expansion of agricultural land use and unsustainable intensification of agricultural practices are among the main direct drivers of land degradation and loss of biodiversity globally (e.g., Foley et al., 2005; Stoate et al., 2009). Urbanization causes environmental change at local and global scales, causing habitat loss and fragmentation, over-exploitation of natural resources, pollution and climate change (e.g., Grimm et al., 2008; Seto et al., 2011; Elmquist et al., 2013). As a consequence of these threats and challenges, urbanization and agricultural land use belong to two of the six main fields of society's transformation towards sustainable development needed to achieve the United Nations 2030 Agenda (e.g. TWI2050, 2018; Sachs et al., 2019). Moreover, both systems can be linked in subnational regional settings - in positive as well as negative ways. Urban and peri-urban agriculture (UPUA) offer promising pathways to promote transformation towards sustainable development (IAASTD, 2009; IPCC, 2019). A number of strategic spatial planning approaches evolved since the 1960s to tackle these challenges and to promote sustainable land use development in urban areas (Albrechts, 2004; Healey, 2006). The concept of Green Infrastructure (GI) has emerged as a spatial planning approach that contributes to sustainable development and copes with urban sprawl (Benedict and McMahon, 2002). As a promising contribution to the development of resilient cities and sustainable urban transformation, it recently gained attention in scientific research. A recent milestone to promote $\mathrm{GI}$ in Europe was the adoption of the European GI Strategy by the European Commission in 2013 as part of the six main targets of the EU Biodiversity Strategy to 2020 (European Commission, 2013). Urban GI (UGI) planning aims to develop multifunctional networks at different urban scales - from urban regional scale to neighborhood scale - interlinked with GI planning at the surrounding landscape scale. It can be defined as "a strategic planning approach that aims to develop networks of green and blue spaces in urban areas, designed and managed to deliver a wide range of ecosystem services and other benefits at all spatial scales" (Hansen et al., 2016). However, the focus of research on UGI planning has mainly been on green urban structures, such as parks, urban forest, building and street green, but it has neglected spatial and functional potentials of utilizable agricultural land or considered small-scale urban gardening activities as one form of UPUA such as rooftop, allotment or community gardening. Still, many open spaces in European cities are dominated by agricultural land, thus making it a relevant spatial factor. Consequently, there is a knowledge gap in how urban and peri-urban utilizable agricultural land can contribute to UGI. Since the last 20 years again, discussion of modern conceptual ideas of UPUA evolved (e.g. Mougeot, 2006), also explicitly with regard to spatial urban planning and design (e.g., Philips 2013; Viljoen and Bohn, 2014). Furthermore, research at farm level, investigating social, economic and environmental functions in urban contexts (e.g., Lohrberg et al., 2016, Piorr et al. 2018) point to linkages to UGI objectives.

Against this background, it's worth to further investigate how UPUA can contribute to the basic conception of GI as an "interconnected network of green spaces that conserves natural ecosystem values and functions and provides associated benefits to human populations" to provide an ecological framework "for environmental, social and economic sustainability" (Benedict and McMahon, 2002). The overarching aim of this thesis is therefore to investigate whether peri-urban farmland can contribute 
to the development of UGI as a strategy to promote sustainable urban development based on three research questions:

- How can peri-urban farmland support the development of multifunctional green space networks based on the two core GI principles connectivity and multifunctionality? (Conceptual understanding)

- Can peri-urban farmland be linked to the UGI conception to develop a strategic planned multifunctional network? (Implications for planning)

- How can peri-urban farmland as a component of UGI promote pathways of transformation towards sustainable urban development? (Overarching)

Within this thesis, 'peri-urban farmland' is understood to emphatically include all of the utilizable ag- ricultural land within the functional urban area under consideration. Thus, utilizable agricultural land consists of all forms of low-intensive and high-intensive farming, whether assigned to UPUA in the narrow or broader sense.

\section{Research approach and methods}

To operationalize Green Infrastructure this work applies the framework for UGI planning as conceptualized by the GREEN SURGE project, addressing four aims for UGI planning and four planning principles (figure 1). Furthermore, the work is structured based on four published articles as part of this cumulative thesis (figure 2).

\section{urban challenges - aims and objectives of urban green infrastructure planning

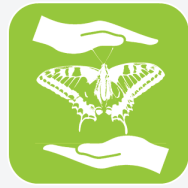 \\ biodiversity conservation \\ support biodiversity, opportunities to interact with nature, and stewardship of nature and ecological processes

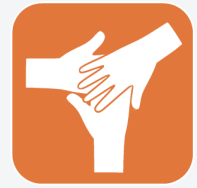 \\ social cohesion \\ support the development of shared values, cooperations and interactions within the community

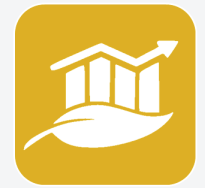 \\ green \\ economy \\ support human well-being and social equity, while reducing environmental risks and depletion of natural resources

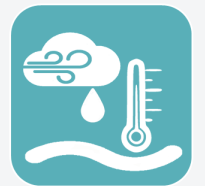 \\ climate change adaptation \\ support capacities to regulate urban climate, improve air quality, and to reduce stormwater flooding}

\section{planning principles}

green-grey integration:

Integration and coordination of urban green spaces with other infrastructure, such as transport systems and utilities

connectivity:

creating green space networks to support and protect biotic, abiotic and social processes, functions and benefits that individual green spaces cannot provide alone

multifunctionality:

enhance the capacity of urban green space to deliver multiple benefits - creating synergies, while reducing conflicts and trade-offs

social inclusion:

Involving collaborative and participatory planning processes that are open to all and incorporate the knowledge and needs of diverse parties

Figure 1. Scheme illustrating the understanding of UGI planning as conceptualized by the GREEN SURGE project (adapted from Hansen et al., 2017). 
Article-I, "Farmland - an Elephant in the Room of Urban Green Infrastructure? Lessons learned from Connectivity Analysis in three German Cities" (Rolf et al. 2018) investigates the potential contributions of peri-urban farmland to connectivity, as one of the two GI key principles using a quantitative GIS-based analysis of structural connectivity. The study is conducted in functional urban areas of the three largest and expanding cities in the federal state of Bavaria in Southeast Germany, namely Munich, Augsburg, Nuremberg, all three belonging to European Metropolitan Regions. The study uses structural connectivity as a surrogate for functional connectivity, supporting a variety of ecological, social and abiotic processes and functions. It focuses on low-intensity farmland as a site-specific characterization (using habitat suitability modeling), hypothesizing that it offers particular potential for multiple functions.

Article-II, "Algorithmic Landscapes meet Geodesign for effective Green Infrastructure Planning - Ideas and Perspectives" (Rolf and Peters 2020) is an ad- ditional methodological excursion and incorporates the habitat suitability modeling approach, as applied in Article-I. It discusses the use of GIS modeling and algorithms to analyze complex ecological interrelations in the landscape. It shows how they help to handle comprehensive environmental data to process them purposefully and to support communication strategies for collaborative GI planning.

Article-III, "A stakeholder Approach, Door Opener for Farmland and Multifunctionality in Urban Green Infrastructure" (Rolf et al. 2019) investigates the contribution of peri-urban farmland to multifunctionality, another GI key principle. Using participatory research to involve stakeholder opinions, this approach evaluates multifunctionality qualitatively. The research area is the peri-urban landscape of the European Metropolitan Region of Malmö, Sweden. The study takes into account the heterogeneity of agricultural land and its diversity of site-specific conditions, potentials and constraints, taking into account both low and high productive farmland.
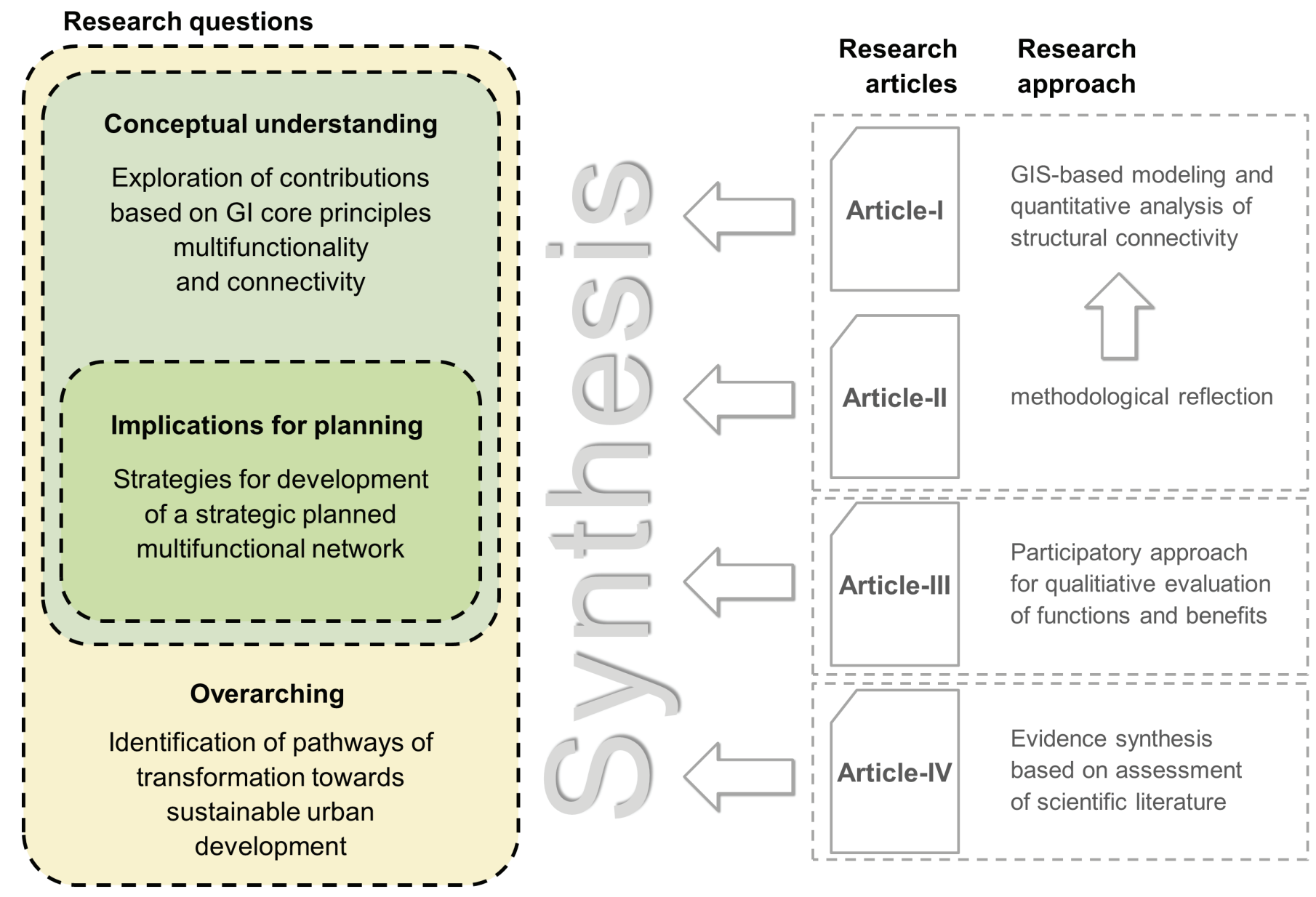

Figure 2. Structure of the thesis and with research approach and contributions of the articles to the research questions. 
Article-IV, "Integrating farmland in Urban Green Infrastructure planning. An evidence synthesis for informed policymaking" (Rolf et al. 2020) is based on a comprehensive literature analysis to analyze if the current state of research supports evidence-based policymaking by arguments that agriculture landscapes can contribute to UGI aims, namely biodiversity conservation, climate change adaptation, green economy development, and social cohesion. A reciprocal approach is applied, evaluating how policymaking at the European level provides a framework to encourage and facilitate UGI development in agriculture landscapes and to address potentials and gaps in evidence-based policymaking that is needed to support transformation.

\section{Key findings}

\subsection{Conceptual understanding - contributions of Gl core principles to develop multifunctional green space networks}

Insights emerge from this work with regard to the development of multifunctional green space networks by peri-urban farmland based on the two GI core principles connectivity and multifunctionality (figure 3).

Referring to connectivity, potential contributions of peri-urban farmland to ecological, social and abiotic functions and benefits are related to structural and functional connectivity. With an emphasis on ecological connectivity, the consideration of semi-natural farmland as part of UGI offers the potential to support the inner urban biodiversity. Further ecological functions can be supported beyond semi-natural farmland, as demonstrated by complementary measures in highly productive agricultural landscapes that also support connectivity and promote networks for wildlife. In addition, two modes emerge, how peri-urban farmland promotes connectivity while looking at social processes and functions. First, farmland corridors contribute to alternative mobility such as walking and cycling, for instance, by linking quarters or districts separated by farmland, thus contributing to the recreation networks, which is being considered as one relevant objective to be provided by UGI. Second, farmland offers promising potential near to residences and neighborhoods for physical activity and wellbeing effects. Furthermore, farmland potentially supports abiotic processes and functions due to connectivity: The general struc-

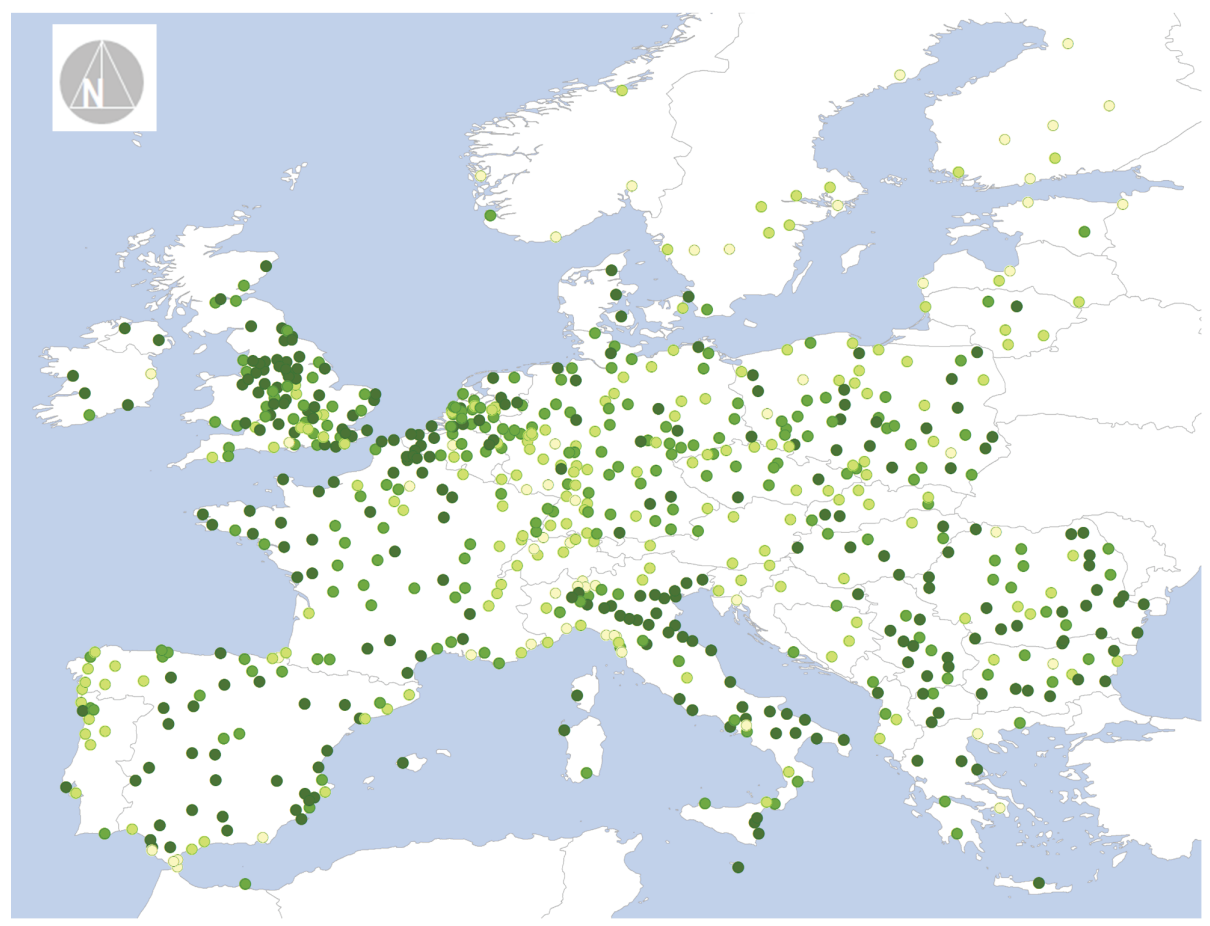

\section{share of open spaces covered by agricultural land within functional urban areas:}

$<25 \%$ share of agricultural land

- $25 \%-50 \%$ share of agricultural land

- $50 \%-75 \%$ share of agricultural land

- > $75 \%$ share of agricultural land

\section{share of agricultural land use forms within urban open spaces across Europe:}

arable land i green urban $(34 \%)$ spaces $(3 \%)$

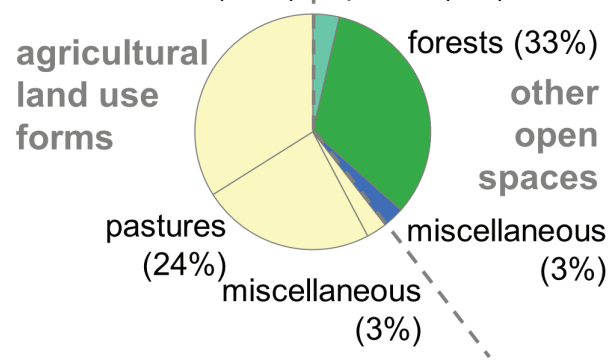

Figure 3. The high share of functional urban areas by utilizable agricultural land - i.e. 'peri-urban farmland' offer spatial potentials contributing to UGI connectivity and multifunctionality (Calculation based in Urban Atlas data (EEA 2012)). 
ture of farmland is suitable for ventilation corridors, thus improving the supply of fresh air and reducing air pollution. Due to high evapotranspiration rates, wet grassland farming systems efficiently function as cooling systems for the urban system. However, modeling approaches are needed to better predict these effects, taking into account the spatial pattern of the agricultural landscape and the urban structure, for instance, to design efficient wind channels. In sum, utilizable agricultural land can contribute to $\mathrm{GI}$ and enhance connectivity, steering ecological, social and abiotic processes and functions. Consequently, it can be argued that peri-urban farmland can purposefully complement UGI as an interconnected network, together with parks, forests and other urban green spaces.

Referring to the core principle of multifunctionality, this thesis gives insights with an emphasis on the landscape level and extends the vast knowledge existing about multifunctionality concept and agriculture at the farm level. Results clearly show that peri-urban farmland offers multiple functions contributing to $\mathrm{Gl}$, thus promoting sustainable land use. The multifunctionality framework is appropriate to promote synergies between different functions and to deal with trade-offs in the peri-urban landscape. The importance of considering and accommodating different values among stakeholders cannot be stressed too much. The participatory approach supported to co-develop scenarios at a fine-grained scale, which helped to consider the complex relationships between different needs, values, their synergies and conflicts and to negotiate strategic objectives, including the identification of priority functions, comprising key functions and additional functions in meaningful bundles suitable for UGI planning. The evidence synthesis conducted furthermore helped to strengthen and refine different multifunctionality options. Hence, these findings provide a knowledge base for UGI planning that will contribute to a better understanding and increased acceptance by stakeholders, and thus promote integration across sectors and scales, which is considered as crucial for effective sustainable planning. Moreover, the results strengthen confidence in the proposition that meaningful bundles of multiple functions suitable for UGI development are strongly related to landscape heterogeneity and its different site characteristics defining agricultural potentials while some relate to farmland of high productivity others assist on sites of less agricultural productivity. This outcome suggests that the spatial allocation of the different strategies needs to be carefully considered to intertwine multiple functions for UGI planning in peri-urban farmland to avoid conflicts and to promote win-win situations between agriculture and UGI planning. Accordingly, one key finding is that successful GI planning taking into account peri-urban farmland, inevitably needs to respond to landscape character. Multifunctionality needs to be considered in both space and time where functions are allocated to different land units (i.e., spatial segregation), and that these functions interact with each other. With this in mind, the GI approach supports looking at multifunctionality beyond the farm level, taking into account multifunctionality at the landscape level, and eventually considering functions and benefits at a territorial scale.

\subsection{Implications for planning - four ways for strategic spatial planning of a multifunctional green space network}

The identification of linkages between peri-urban farmland and the UGI concept show their suitability for the strategic spatial planning of multifunctional green space networks that address major urban challenges, namely biodiversity conservation, climate change adaptation, green economy development, and social cohesion. Four different spatial planning strategies have emerged that show the ability to link peri-urban farmland with the UGI conception (i.e., to develop a multifunctional green space network). These are the connecting, the productive, the integrated, and the adapted way (figure 4).

These strategies may be understood as ideal types, representing an abstraction of real, existing individual phenomena that intertwine physical, ecological, social, as well as the economic functions of a multifunctional UGI network. They have been scaled to elements suitable for discussing options for UGI development. Furthermore, they relate to the basic network conception of hubs, links and sites (cf. Benedict and McMahon, 2006). Thus, these four strategies have the ability to stimulate discussion about how UGI planning can and should incorporate uti- 


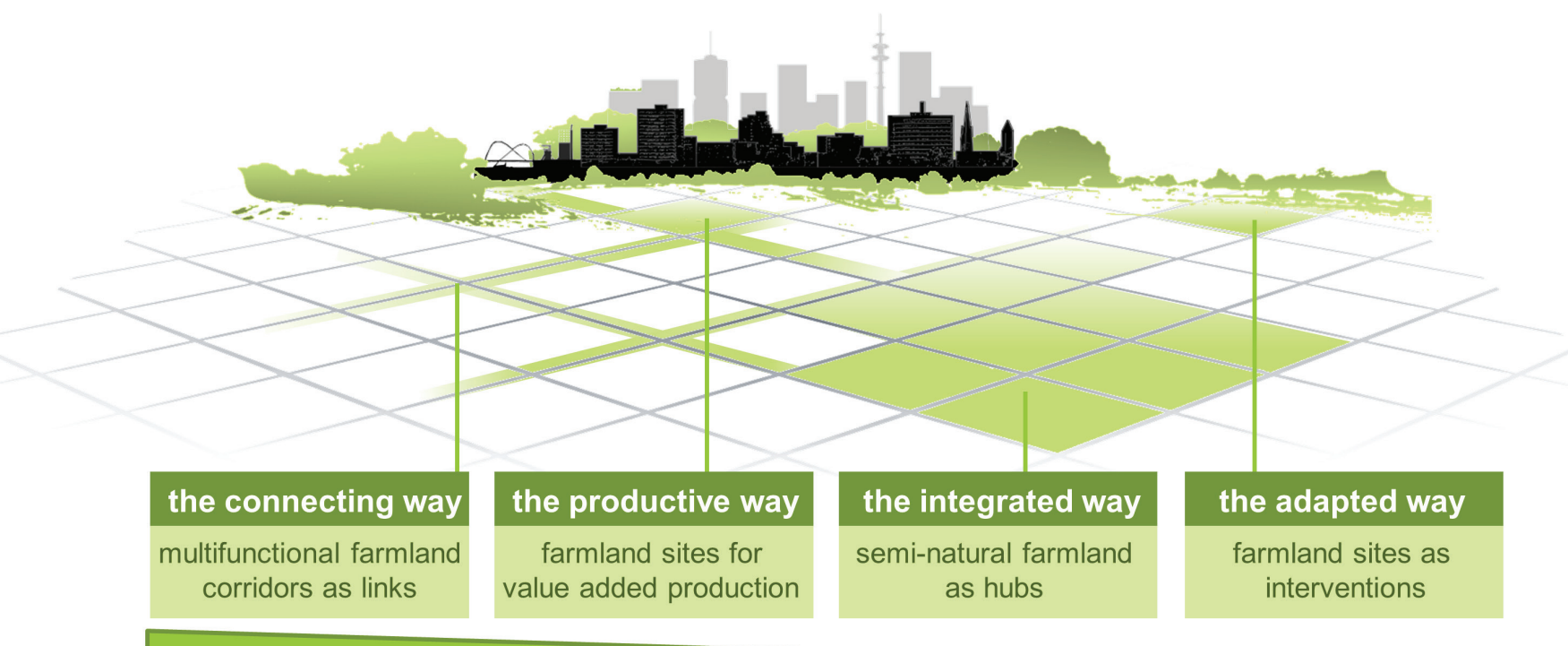

agricultural commodities

non-commodity outputs

Figure 4. Schematic illustration of four ways linking farmland with the UGI concept and their relation to agricultural commodities and non-commodity outputs.

lizable agricultural land, especially the agriculturally dominated landscape at the urban fringe and its surroundings.

\section{As a first spatial planning strategy - the connect-} ing way: multifunctional farmland corridors as links - this work suggests 'multifunctional farmland corridors' as a 'pathway' to develop UGI links within agriculturally dominated green belts or rings at the urban fringe. Multifunctional farmland corridors are understood as linear network elements in a highly productive agricultural landscape that do not interfere with on-site productivity (figure 5). They signif- icantly contribute to a functional recreational network by offering opportunities for leisure activities (e.g., walking, cycling, riding) and enhancing accessibility to the wider landscape for urban dwellers. This option gains high acceptance and appreciation by a number of different stakeholders, including farmers as key actors, due to its potentials for a variety of functions. Several UGI objectives, besides recreation, can be underpinned by established scientific evidence. These comprise accompanying margin strips that promote dispersal within the landscape matrix and provide small habitat opportunities for wildlife

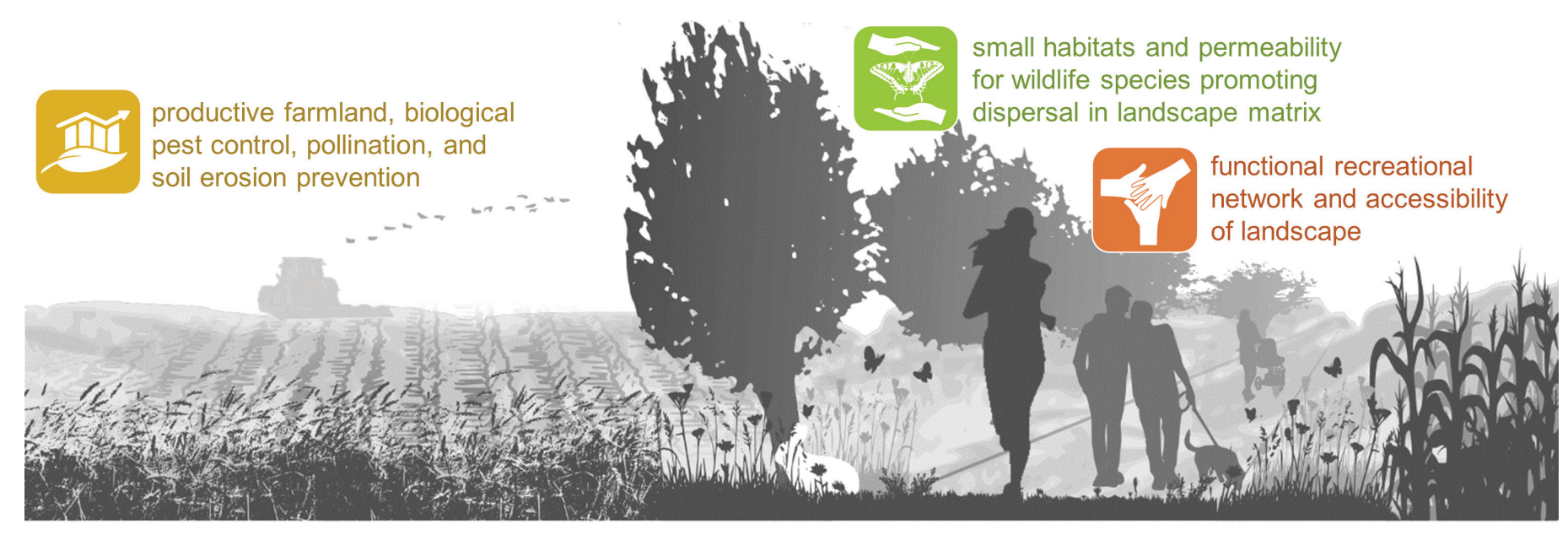

Figure 5. Illustration of multifunctional farmland corridors with potential key functions and benefits addressing urban challenges. 
thereby augmenting urban biodiversity. Furthermore, farmland corridors can be beneficial for farmers by contributing to biological pest control and pollination or prevent soil erosion. Consequently, this thesis suggests multifunctional farmland corridors as a striking example of a UGI network element that can be integrated into high intensively managed agricultural dominated landscape matrix to coherently and mutually reinforces multiple functions.

The second spatial planning strategy - the productive way: sites for value added farm production - also relates to sites that are of high productivity. In comparison to the previous type, the productive way offers an opportunity to combine UGI development with the agricultural production cycle onsite that benefits directly from the site productivity. It aims to benefit from the fertility of the sites for food production with the inclusion of further social functions, such as recreation, regeneration, and education, into agricultural production, and which offers new farming models and relationships between consumer and producer (figure 6). Several ideas have been identified within this work, such as renta-field farms or self-picking farms (e.g., fruit, vegetables, flowers) that enable an 'on-field' experience for citizens in their spare time or at the weekend, relating to rather small scaled urban gardening and urban agriculture activities (e.g., Lovell 2010; Aerts et al., 2016) as well as to UGI in the wider agricultural landscape more explicitly. Furthermore, these results provide established evidence that support the idea that UGI development does not need to lead to the exclusion of economic benefit for agricultural businesses, but may even promote sustainable eco- nomic growth in the agricultural sector. Accordingly, 'the productive way' offers opportunities for alternative business models and new income situations. In addition, it contributes to the efficiency of supply chains, constructs social activities and networks, stimulating active involvement and may function as a node to strengthen relationships between citizens and farmers. Consequently, the consideration of 'productive farmland' as a spatial planning strategy for UGI has the potential to support the green economy in several ways, promoting transition from conventional farming to alternative models.

In contrast, the third spatial planning strategy - the integrated way: semi-natural farmland as hubs - is more related to sites of low agricultural productivity. As supported by the quantitative analysis of this work, there may be significant spatial potential for low-intensity farmland within the peri-urban landscape. The integrated strategy reflects region-specific management practices that are constrained by prevailing environmental conditions (soil, climate, topography) and their geophysical constraints (cf. Beaufoy et al., 1994). Accordingly, management can be very different, with or without livestock or mixed. The farmland may vary in character, ranging from grassland systems, such as meadows and pastures, to agroforestry and cropping systems, like pastoral woodland, orchards, olive groves and other arable systems (c.f. Oppermann et al., 2012). Structured as a mosaic of cultivation and semi-natural vegetation, they often have integrated historical features, such as hedgerows, stone walls, ponds, or trees (ibid.). As discussed with the different stakeholders and supported by evidence, semi-natural farmland provides

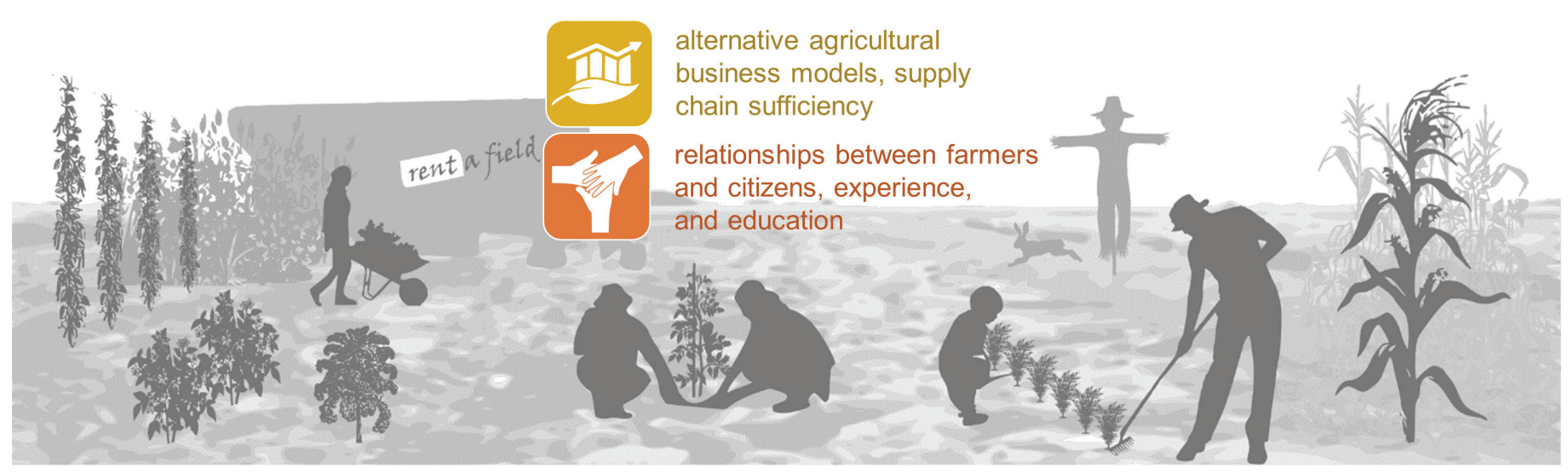

Figure 6. Illustration of productive farmland with potential key functions and benefits addressing urban challenges. 


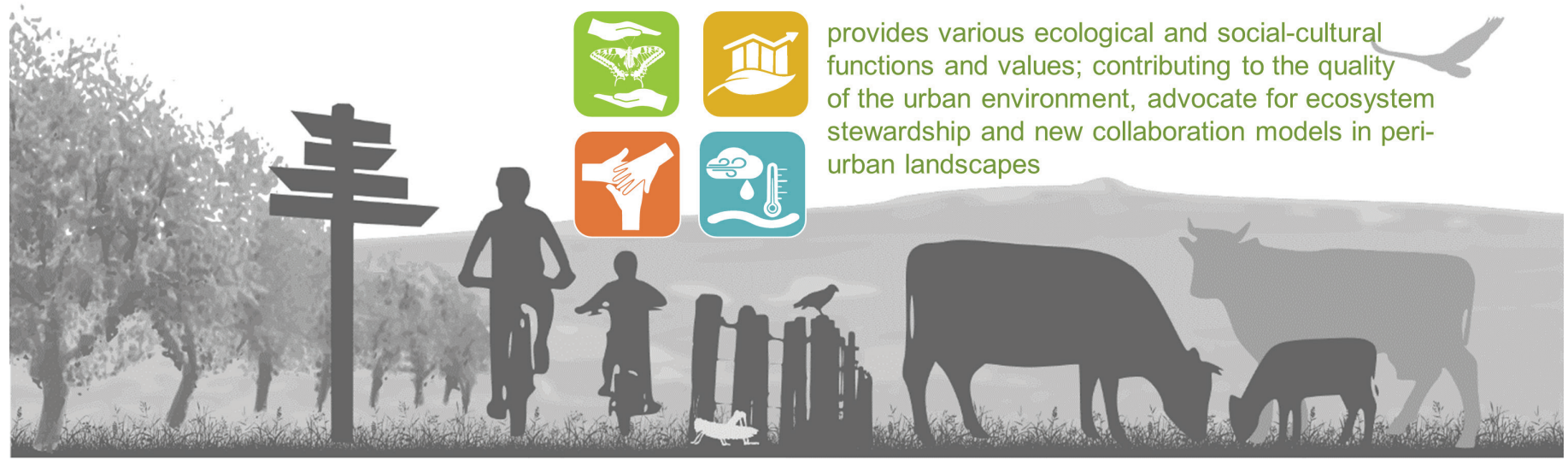

Figure 7. Illustration of semi-natural farmland with potential key functions and benefits addressing urban challenges.

a number of positive externalities from agriculture, i.e., integrated amenities, such as ecological and social- cultural functions and values contributing to the quality of the urban environment (figure 7). If certain EU agri-environmental indicators apply, semi-natural farmland can be defined as having "high nature value" (HNV). Accordingly, this thesis suggests semi-natural farmland as hubs, serving as building blocks for the UGI network, suitable for conservation of biodiversity and the maintenance of natural ecological processes (cf. Benedict and McMahon, 2006). If protected as areas under 'Habitats Directive' (Council Directive 92/43/EEC) or 'Birds Directive' (Directive $2009 / 147 / E C)$, they may, in addition, interlink different scales, the regional UGI with the Natura 2000 network as the backbone of trans-european green infrastructure (cf. European Commission, 2019). UGI planning ought to support the management of semi-natural farmland in the peri-urban landscape, to prevent areas from agricultural abandonment or to avoid intensification. However, this does not necessarily need to lead to museumization. Rather it advocates semi-natural farmland as a vital part of the urban, that promotes ecosystem stewardship and collaboration, generating and catalyzing new pathways for innovative ecosystem management leading to more sustainable and balanced land use and urban growth. As a consequence, the results show that UGI, as an integrated cross-sectoral spatial planning approach, also offers opportunities to contribute to the development of future-oriented pathways to the conservation semi-natural farmland.

The fourth spatial planning strategy - the adapted way: sites for farming as interventions - sheds light on the introduction of adapted farm management at sites that have not been under agricultural cultivation previously to promote non-commodity output values to introduce and/or support processes and functions with non-commodity, as alternative management contributing to UGI (figure 8). Grazing

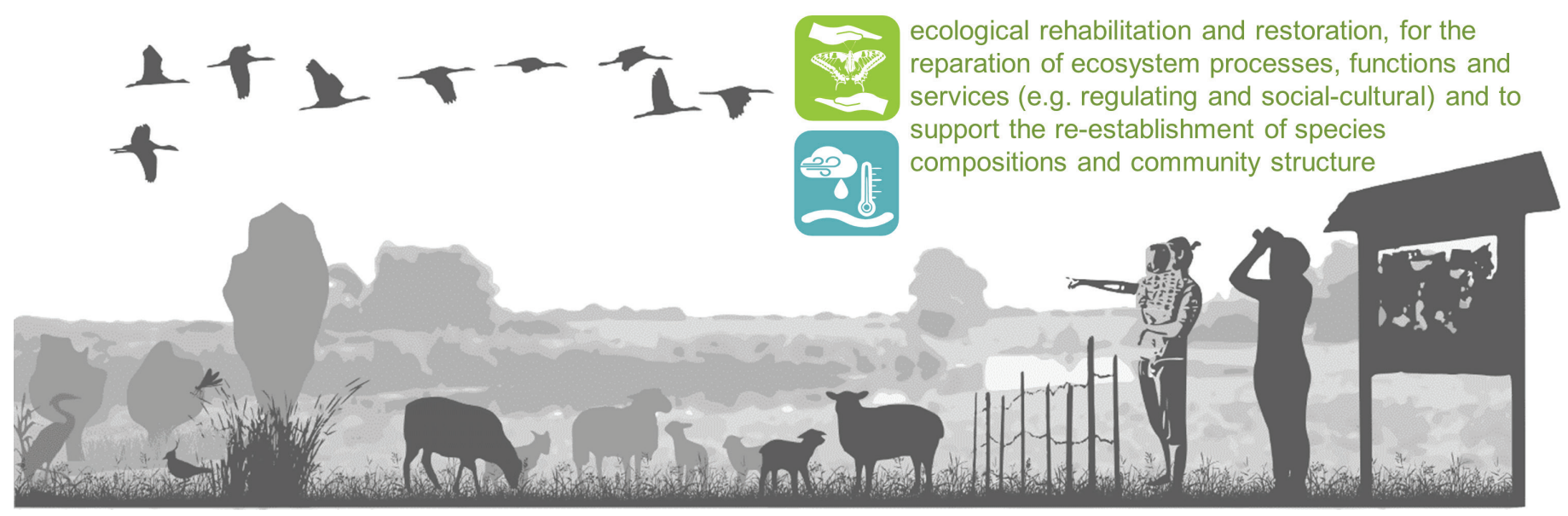

Figure 8. Illustration of adapted farmland with potential key functions and benefits addressing urban challenges. 
management offers opportunities for active ecological rehabilitation and restoration, respectively, for the reparation of ecosystem processes, functions and services and to support the re-establishment of species compositions and community structure. This option bears potentials of social-cultural services farms for nature experience and education for urban dwellers, school classes, etc. especially when accessible and integrated with a recreation network. Inner-urban adapted farmland management, such as grazing can be an alternative for urban greenery as part of UGI. Farmland contributes to inner-urban stormwater retention sites, supplementing green river banks and inner-city fields as ventilation corridors. In sum, adapted farming may be understood as an intervention to complement or further develop UGI by providing additional functions. Adapted farming presents new opportunities for cooperation with farmers and to develop new business models for UGI maintenance. Nevertheless, the study has also shown that agricultural production is of subordinate relevance at such sites. If farming management is supposed to support functions and provide benefits to the urban people, strong incentives are needed to involve farmers in such interventions.

\subsection{Overarching - farmland and UGI as an arena for sustainability transitions}

It is believed that due to the long development history of 'mature' cities and to their existing infrastructure, the resulting path dependencies are difficult to change (WBGU, 2016). Nevertheless, urban agglomerations are considered to provide a fertile medium for creativity that can promote the innovation of transformation pathways towards sustainability (e.g., Ernstson et al., 2010; Nevens et al., 2013; Loorbach and Shiroyama, 2016). This final reflection sheds light on the outcomes of this thesis, suggesting that peri-urban farmland linked with UGI planning can support such transformative processes.

In particular, the inherent principle of multifunctionality largely contributes to the generation of co-benefits that are considered crucial to trigger transformative processes. Co-benefits generate shared motivations, which motivate collaborative dynamics. As a self-reinforcing cycle of mutual trust and understanding, this legitimizes and stimulates ongoing collaboration, sustaining principled engagement, and vice versa (Emerson et al., 2012). This ongoing collaboration supports future processes of problem solving and the unfolding creativity reveals new pathways, thus, promoting transformational and systemic change. The idea that farmland and UGI may function as a collaboration arena for sustainable development can be further discussed by reflecting on the participatory approach in the light of the four principles for co-knowledge production in sustainability research as proposed by Norström et al. (2020) - proposing that processes should be context-based, pluralistic, interactive, and goal-oriented. They are considered as essential for high-quality knowledge co-production promoting sustainability and can be related as follows. The integration of farmland in the UGI planning process (1) supports the development of context-specific solutions, by taking needs and values (including economic) of the various actors of the region into account; (2) offers opportunities for pluralistic collaboration of researchers and local actors from different sectors to generate knowledge, and (3) offers opportunities for interactive processes among the different stakeholders involved. Furthermore, (4) the overarching goal of the development of UGI, with its different benefits that can be shared among participants, clearly benefits from goal-oriented and problem-focused approaches for knowledge creation.

The results of this thesis indicate that linking peri-urban farmland with the UGI concept is a promising field of action that can lead to the development of new pathways for urban transformation towards sustainable urban development. They contribute to a better understanding and contextualization of farmland and its potentials as part of UGI. Consequently, the presentation of the results conclude by advocating the multiple benefits of farmland and fosters an appreciation of the need for its maintenance as a vital part of the city. Finally, they assert that sustainable pathways will evolve that deal with land use competition and facilitate synergies that can maintain farmland and lead to a rethinking of the urban-rural divide. 


\section{Conclusions}

This thesis contributes to the conceptual understanding of UGI as a strategic spatial planning approach that incorporates both inner-urban utilizable agricultural land and the agriculturally dominated landscape at the urban fringe and its surroundings. Several insights emerge with regard to the two GI core principles connectivity and multifunctionality. One striking outcome is that peri-urban farmland can contribute to $\mathrm{Gl}$ and enhance connectivity, steering ecological, social and abiotic processes and functions. Hence, peri-urban farmland can purposefully complement UGI as an interconnected network, together with parks, forests and other urban green spaces. As another outcome, this work has strengthened confidence that meaningful bundles of multiple functions suitable for UGI development are strongly related to landscape heterogeneity and its different site characteristics that define agricultural potentials and constraints. As illustrated by the different strategies proposed, some meaningful bundles relate to farmland of high agricultural productivity while others assist sites of less agricultural productivity. It can be concluded that spatial allocation of the different multifunctionality planning strategies must be carefully considered to avoid conflicts and to promote win-win situations between agriculture and UGI planning.

This thesis introduces four different strategies for spatial planning of the contribution of peri-urban farmland to UGI as a strategically planned multifunctional network. These strategies can be used as recommendations to stimulate UGI planning for incorporating inner-urban utilizable agricultural land and the agriculturally dominated landscape at the urban fringe and its surroundings. However, these findings need to be carefully applied and might need to be adapted to individual situations. More importantly, they need to be negotiated with the stakeholders in each region, because acceptance and successful implementation strongly depends on this. Nevertheless, these strategies offer promising starting points, because this work has proven general acceptance by different stakeholders including farmers as key actors.
In addition, conclusions about UPUA can be drawn. First, the thesis extends the knowledge of UPUA and multifunctionality that usually focused at the farm level. As such, the conceptual linkage between peri-urban farmland and UGI translates the benefits and social, economic and environmental functions between the spatial scales, from the farm level to the landscape level. Second, although UPUA has been discussed in the UGI context, research tended to focus on small-scale activities. The linkage of peri-urban farmland with the UGI concept highlights that the wider utilizable agricultural landscape can contribute to an interconnected network of multifunctional green spaces to provide multiple benefits to the urban system. These findings widen the current debate about UGI planning that often excludes utilizable agricultural land. Furthermore, they expand knowledge about the multifunctionality of UPUA by providing a detailed picture of UGI aims and objectives. Hence, this thesis provides knowledge about how the UGI concept can link urban and agricultural systems in the peri-urban to successfully address urban challenges such as biodiversity conservation, climate change adaptation, green economy development, and social cohesion.

Finally, opportunities to support transformation towards sustainable urban development arise from the linkage of peri-urban farmland and the UGI conception. In particular, the inherent GI principle of multifunctionality endorses the idea of co-benefits that are considered crucial to trigger transformative processes. This is further supported by reflecting on the participatory approach of this work in the light of the four principles for co-knowledge production in sustainability research, which leads to the conclusion that the linkages support processes that are context-based, pluralistic, interactive and goal-oriented. Thus, the linkage of peri-urban farmland with the UGI concept is a promising action field for the development of new pathways for urban transformation towards sustainable urban development.

Despite the outcomes of this thesis, limitations remain to be acknowledged. First, the thesis has only investigated the two core principles of $\mathrm{Gl}$, connectivity and multifunctionality. There are several other principles considered important for successful UGI planning, such as the integration and coordination of 
green with grey infrastructure, multiscale planning, as well as the design of strategic, cooperative and socially inclusive planning processes. These all need to be looked at more specifically. Further research may help to better understand overlaps and interrelations between the different principles for better integration of peri-urban farmland in UGI planning.

Second, there are still knowledge gaps with regard to some important regulating functions to be tackled by UGI, including local climate regulation to support climate change adaptation as one of the main objectives assigned to UGI planning. This work gathers evidence about how farmland potentially supports cooling processes due to their general structure suitable for ventilation corridors and evapotranspiration rates of wet grassland farming systems. Still, it is important to better understand effects of the spatial pattern of the agricultural landscape and the urban structure, for instance, to design efficient wind channels. As pointed out in this thesis, modeling approaches can help to predict these effects and to support planning that considers farmland for urban climate regulation in urban development planning. In addition, quantitative biophysical valuations, more sociocultural research is needed. Although this work integrates a participatory research approach to qualitatively evaluate functions and benefits based on stakeholder opinion, more research with regard to the sociocultural valuation of ecosystem services provided by farmland in an explicit peri-urban context is needed. This would help to understand people's attitudes and perceptions better and identify relevant factors for taking co-benefits into account, relevant to the motivation of collaboration and the support of transformational and systemic change towards sustainable urban development. This also includes the involvement of farmers as key actors to identify factors for successful partnerships between planning and farming.

Finally, agriculture in Europe strongly depends on European policy frameworks, and urban policymaking at the local level reflects this limitation. Although this work tackles some aspects of policy integration at the European level, more research on this topic is needed. Besides identifying opportunities for supporting policymaking at the EU level, it is also important to identify mechanisms that support policy integration at the local level that are necessary to support the agricultural sector effectively during transformation processes.

\section{About this work}

This work is a synthesis of a cumulative dissertation for the degree of doctor rerum naturalium (Dr. rer. nat.) in Landscape Management, entitled "Peri-urban farmland included in green infrastructure strategies promotes transformation pathways towards sustainable urban development", submitted to the Institute of Environmental Science and Geography, Faculty of Sciences at the University of Potsdam, in 2020. This synthesis is an extract from this thesis, published at the institutional repository of the University of Potsdam for long-term archiving DOI:10.25932/publishup-47700

It comprises results of four published articles:

Rolf, W., Peters, D., Lenz, R., Pauleit, S. 2018. Farmland - an Elephant in the Room of Urban Green Infrastructure? Lessons learned from connectivity analysis in three German cities. Ecological Indicators 94(2). DOI:10.1016/j. ecolind.2017.06.055

Rolf, W., Pauleit, S., Wiggering, H. 2019. A stakeholder approach, door opener for farmland and multifunctionality in Urban Green Infrastructure. Urban Forestry \& Urban Greening 40. DOI:10.1016/j.ufug.2018.07.012

Rolf, W, Diehl, K., Zasada, I., Wiggering, H. 2020. Integrating farmland in Urban Green Infrastructure. An evidence synthesis for informed policymaking. Land Use Policy DOI:10.1016/j. landusepol.2020.104823

Rolf, W., Peters, D. 2020. Algorithmic Landscapes meet Geodesign for effective Green Infrastucture Planning - Ideas and Perspectives. Journal of Digital Landscape Architecture, 5-2020, DOI:10.14627/537690049 


\section{Acknowledgements}

This work was partly made possible by the research project 'GREEN SURGE - Green Infrastructure and Urban Biodiversity for Sustainable Urban Development and the Green Economy', funded by the European Commission Seventh Framework Programme (FP7-ENV.2013.6.2-5-603567) and through the research and development project 'Green Infrastructure in urban spaces: Bases, planning and implementation in integrated urban development' funded by the Federal Agency for Nature Conservation (BfN) with funds provided by the Federal Ministry for the Environment, Nature Conservation, Building and Nuclear Safety (FKZ 351582 0800). Furthermore, I thank all people colleagues that supported my work thoroughly in many different ways, in particular my supervisors Hubert Wiggering and Stephan Pauleit, Wolfgang Haber as mentor as well as further co-authors of the different published articles of this cumulative thesis Katharina Diehl, Roman Lenz, Dave Peters and Ingo Zasada.

\section{References}

Aerts, R.; Dewaelheyns, V., Achten, W.M.J, 2016. Potential ecosystem services of urban agriculture: a review. DOI:10.7287/peerj.preprints.2286v1

Albrechts, L., 2004. Strategic (Spatial) Planning Reexamined. Environ Plann B Plann Des 31 (5), 743-758. DOI:10.1068/b3065

Beaufoy, G., Baldock, D., Clark, J., 1994. The Nature of Farming. Low Intensity Farming Systems in Nine European Countries. Institute for European Environmental Policy, London.

Benedict, M.A., McMahon, E.T., 2002. Green infrastructure: Smart conservation for the 21st century. Renewable Resources Journal (20), 1217.

Benedict, M.A., McMahon, E.T., 2006. Green infrastructure: Linking landscapes and infrastructures. Island Press, Washington,
London, 299 pp.

EEA-European Environment Agency 2012. European Urban Atlas. Retrieved from http://www.eea. europa.eu/data-and-maps/data/urban-atlas

Elmqvist, T., M. Fragkias, J. Goodness, B. Güneralp, P.J. Marcotullio, R.I. McDonald, S. Parnell, M. Schewenius, Sendstad, M., Seto, K.C., Wilkinson, C., Alberti, M., Folke, C., Frantzeskaki, N., Haase, D., Katti, M., Nagendra, H., Niemelä, J., Pickett, S.T.A., Redman, C. L., Tidball, K. 2013. Stewardship of the biosphere in the urban era. 719-746. In: Elmqvist, T., Fragkias, M., Goodness, J., Güneralp, B., Marcotullio, P.J., McDonald, R.I., Parnell, S., Schewenius, M., Sendstad, M., Seto, K.C., Wilkinson, C., 2013. Urbanization, Biodiversity and Ecosystem Services: Challenges and Opportunities. Springer Netherlands, Dordrecht.

Emerson, K., Nabatchi, T., Balogh, S., 2012. An Integrative Framework for Collaborative Governance. Journal of Public Administration Research and Theory 22 (1), 1-29. DOI:10.1093/ jopart/mur011

Ernstson, H., van der Leeuw, S.E., Redman, C.L., Meffert, D.J., Davis, G., Alfsen, C., Elmqvist, T., 2010. Urban transitions: on urban resilience and human- dominated ecosystems. Ambio 39 (8), 531-545. DOI:10.1007/S13280-010-0081-9

European Commission, 2013. Communication from the Commission to the European Parliament, the Council, the European Economic and Social Committee and the Committee of the Regions. Green Infrastructure (GI)-Enhancing Europe's Natural Capital. COM(2013) 249 final. Brussels

European Commission, 2019. Commission staff working document. Guidance on a strategic framework for further supporting the deployment of EU-level green and blue infrastructure. SWD(2019) 193 final. Brussels

Foley, J. A., R. DeFries, G. P. Asner, C. Barford, G. Bonan, S. R. Carpenter, F. S. Chapin, M. T. Coe, G. C. Daily, H. K. Gibbs, J. H. Helkowski, T. Holloway, E. A. Howard, C. J. Kucharik, C. Monfreda, J. A. Patz, I. C. Prentice, N. Ramankutty and P. K. Snyder, 2005. Global Consequences of Land Use. Science 309 (5734), 570-574. DOI:10.1126/science.1111772 
Grimm, N.B., Faeth, S.H., Golubiewski, N.E., Redman, C.L., Wu, J., Bai, X., Briggs, J.M., 2008. Global change and the ecology of cities. Science (New York, N.Y.) 319 (5864), 756-760. DOI:10.1126/ science.1150195

Hansen, R., Rolf, W., Santos, A., Luz, A.C., Száras, L., Tosics, I., Vierikko, K., Rall, E., Davies, C., Pauleit, S., 2016. Advanced Urban Green Infrastructure Planning and Implementation - Innovative Approaches and Strategies from European Cities. Deliverable 5.2. GREEN SURGE report. DOI:10.13140/RG.2.1.3948.9680

Healey, P., 2006. Urban Complexity and Spatial Strategies. Routledge.

IAASTD, 2009. Agriculture at a Crossroads: International Assessment of Agricultural Knowledge, Science and Technology for Development Synthesis Report - A Synthesis of the Global and Sub-Global IAASTD Reports. Library of Congress, Washington, D.C., London, 106 pp.

IPBES 2019. Global assessment report on biodiversity and ecosystem services of the Intergovernmental Science-Policy Platform on Biodiversity and Ecosystem Services. Chapter 1 (Draft form 31 May 2019): Assessing a planet in transformation: Rationale and approach of the IPBES Global Assessment on Biodiversity and Ecosystem Services.

IPCC 2019. IPCC Special Report on Climate Change and Land. Executive summary from Chapter 1. (Draft form 7 August 2019)

Lohrberg, F., Lička, L., Scazzosi, L., Timpe, A., 2016. Urban agriculture Europe. Jovis, Berlin, 230 pp.

Loorbach, D., Shiroyama, H., 2016. The Challenge of Sustainable Urban Development and Transforming Cities, in: Loorbach, D., Wittmayer, J.M., Shiroyama, H., Fujino, J., Mizuguchi, S. (Eds.), Governance of Urban Sustainability Transitions, vol. 11. Springer Japan, Tokyo, pp. 3-12.

Lovell, S.T., 2010. Multifunctional Urban Agriculture for Sustainable Land Use Planning in the United States. Sustainability 2 (8), 2499-2522. DOI:10.3390/su2082499
MEA - Millennium Ecosystem Assessment, 2005. Ecosystems and human well-being. Island Press, Washington, DC, $560 \mathrm{pp}$.

Mougeot, L.J.A., 2006. Growing better cities: Urban agriculture for sustainable development. International Development Research Centre, Ottawa, xix, 97

Nevens, F., Frantzeskaki, N., Gorissen, L., Loorbach, D., 2013. Urban Transition Labs: co-creating transformative action for sustainable cities. Journal of Cleaner Production 50, 111-122. DOI:10.1016/j.jclepro.2012.12.001

Norström, A.V., Cvitanovic, C., Löf, M.F., West, S., Wyborn, C., Balvanera, P., Bednarek, A.T., Bennett, E.M., Biggs, R., Bremond, A. de, Campbell, B.M., Canadell, J.G., Carpenter, S.R., Folke, C., Fulton, E.A., Gaffney, O., Gelcich, S., Jouffray, J.-B., Leach, M., Le Tissier, M., Martín-López, B., Louder, E., Loutre, M.-F., Meadow, A.M., Nagendra, H., Payne, D., Peterson, G.D., Reyers, B., Scholes, R., Speranza, C.I., Spierenburg, M., Stafford-Smith, M., Tengö, M., van der Hel, S., van Putten, I., Österblom, H., 2020. Principles for knowledge coproduction in sustainability research. Nat Sustain 461, 472. DOI:10.1038/s41893-019-0448-2

Philips, A., 2013. Designing urban agriculture: A complete guide to the planning, design, construction, maintenance and management of edible landscapes. John Wiley and Sons Inc, Hoboken, New Jersey, 1 online resource.

Piorr, A., Zasada, I., Doernberg, A., Zoll, F., and Ramme, W., 2018. Research for AGRI Committee - Urban and Peri-urban Agriculture in the EU, European Parliament, Policy Department for Structural and Cohesion Policies, Brussels. DOI:10.2861/953859

Sachs, J.D., Schmidt-Traub, G., Mazzucato, M., Messner, D., Nakicenovic, N., Rockström, J., 2019. Six Transformations to achieve the Sustainable Development Goals. Nature Sustainability. DOI:10.1038/s41893-019-0352- 9

Seto, K.C., Fragkias, M., Güneralp, B., Reilly, M.K., 2011. A meta-analysis of global urban land expansion. PloS one 6 (8), e23777. DOI:10.1371/ journal.pone.0023777 
Stoate, C., Báldi, A., Beja, P., Boatman, N.D., Herzon, I., van Doorn, A., Snoo, G.R. de, Rakosy, L., Ramwell, C., 2009. Ecological impacts of early 21st century agricultural change in Europe - A review. Journal of Environmental Management 91 (1), 22-46. DOI:10.1016/j.jenvman.2009.07.005

TWI2050 - The World in 2050, 2018. Transformations to Achieve the Sustainable Development Goals. Report prepared by The World in 2050 initiative. International Institute for Applied Systems Analysis (IIASA). Laxenburg, Austria.

Viljoen, A., Bohn, K., 2014. Second nature urban agriculture: Designing productive cities. Routledge, Taylor \& Francis Group, Abingdon, Oxon, New York, xi, 300.

WBGU, German Advisory Council on Global Change, 2016. Humanity on the move: Unlocking the transformative power of cities: Flagship report. Berlin, $514 \mathrm{pp}$ 